\title{
Analytical solution for the resistance of composite beams subjected to bending
}

\author{
Marek Lechman ${ }^{1, *}$ \\ ${ }^{1}$ Instytut Techniki Budowlanej, Department of Building Structures, Geotechnics and Concrete, \\ 00-611 Warsaw, ul. Filtrowa 1, Poland
}

\begin{abstract}
The paper deals with the resistance of steel and concrete composite beams, named $\mathrm{BH}$ beams, subjected to bending. They are structurally connected with prefabricated or cast in situ slabs, forming floor slab system. The beams under consideration consist of the reinforced concrete (RC) rectangular core placed inside a reversed TT welded profile. The stress-strain relationship for concrete in compression of the RC core is assumed for nonlinear analysis according to Eurocode 2. For reinforcing and profile steels linear elastic - ideal plastic model is applied. The normalized ultimate bending moment determining the resistance of the $\mathrm{BH}$ beam is derived by integrating the equilibrium equations of the bending moments about the horizontal axis of the $\mathrm{RC}$ core rectangle, taking into account the physical and geometrical relationships. The presented model was verified by tests carried out on two BH beams subjected to bending. The comparisons made indicated good convergence between the analytical solution and the experimental results in ultimate bending moments.
\end{abstract}

\section{Introduction}

In recent years, newly designed floor slab systems have been the subject of particular interest of civil engineers and researchers due to their importance in the engineering practice. The systems under consideration consist of steel and concrete composite beams, named $\mathrm{BH}$ beams, structurally connected with prefabricated or cast in situ slabs [1-5]. General rules for the design of these structures are given in the relevant codes [6 - 8]. The considerations of this paper are focused on the analytical solution for determining the resistance of the $\mathrm{BH}$ beams subjected to bending. Two types of the $\mathrm{BH}$ beams designated as $\mathrm{BH} 27-350$ and $\mathrm{BH}$ 20-300 are considered. They consist of the reinforced (RC) rectangular core placed inside a reversed TT welded profile, as shown in Fig. 1 and Fig. 4. The floor slabs are supported on lower flanges of the steel profile part of the composite beam to provide a flat lower surface of the finished floor. In order to ensure the demanded bond between these components, a number of reinforced concrete studs are used. They were designed as a set of horizontal rebars passing through the perforated webs of the beam and anchored in the slabs. In the case of separate $\mathrm{BH}$ beams, steel studs are applied with the spacing of $0.3 \mathrm{~m}$. The results of FEM modelling of failure behaviour of $\mathrm{BH}$ beams revealed that significant differences in the

\footnotetext{
* Corresponding author: m.lechman@itb.pl
} 
ultimate bending moments occur compared to the bending test results. Therefore, the crosssectional analysis is proposed and employed. It adequately describes BH behaviour at failure. This approach consists in the derivation of analytical formulae for the normalized ultimate bending moment determining the resistance of the $\mathrm{BH}$ beam.

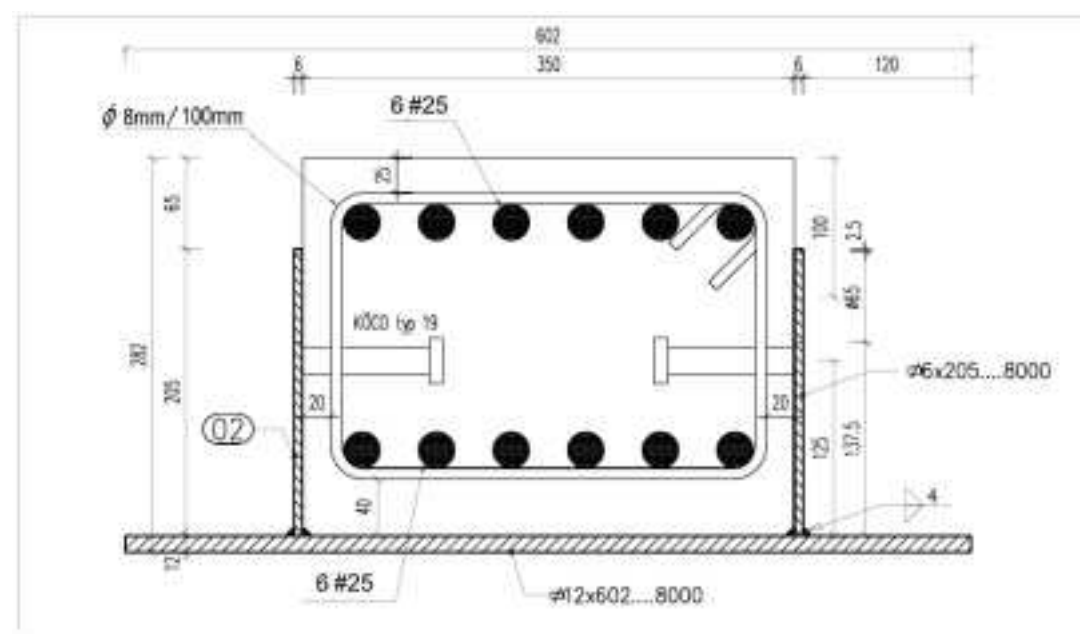

Fig. 1. The cross-section of the composite beams under consideration.

\section{Derivation of formulae}

In the presented considerations, the following assumptions are introduced:

$\circ$ plane sections remain plane,

- elasto-plastic stress-strain relationship for concrete and reinforcing and profile steels are used,

- the tensile strength of concrete is ignored,

$\circ \quad$ the demanded bond between the RC core and the steel profile is ensured.

The stress-strain relationship for concrete $\sigma_{c}-\varepsilon_{c}$ in the compression of the RC core is assumed for nonlinear structural analysis according to Eurocode 2 (Fig. 2), [9]:

$$
\sigma_{c}=\left(k \eta-\eta^{2}\right) /(1+(k-2) \eta) f_{c m},
$$

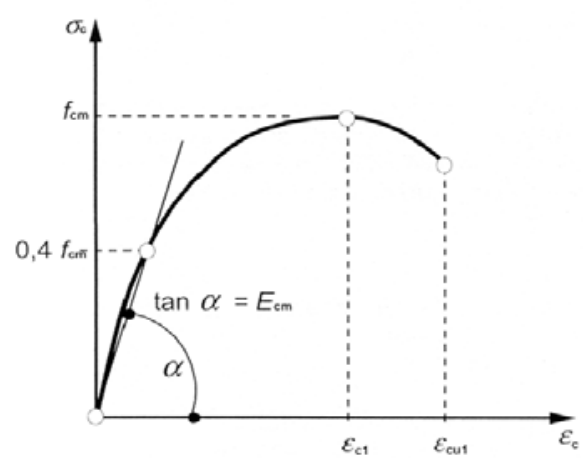

Fig. 2. The stress-strain relation for concrete in compression. 
where: $\eta=\varepsilon_{c} / \mathcal{E}_{c l}, \mathcal{E}_{c l}$ - the strain at peak stress on the $\sigma_{\mathrm{c}}-\mathcal{E}_{\mathrm{c}}$ diagram, $f_{c m}$ - the mean compressive strength of concrete, $k=1,05 E_{c m}\left|\varepsilon_{c 1}\right| / f_{c m}, E_{c m}$ - secant modulus of elasticity of concrete. This stress-strain relation adequately represents the behavior of concrete by introducing four parameters: $f_{c m}, \varepsilon_{c l}, \varepsilon_{c u}$ and $E_{c m}$. For reinforcing and profile steels, characterized by yield stresses $f_{y k}, f_{H y k}$, respectively, linear elastic - ideal plastic model is applied and described by the following formulae:

$$
\begin{array}{lr}
\sigma_{s}=\frac{f_{y k}}{\mathcal{E}_{s s}} \varepsilon & \text { for }-\varepsilon_{s s} \leq \varepsilon \leq \mathcal{E}_{s s} \\
\sigma_{s}=f_{y k} & \text { for } \varepsilon \geq \mathcal{E}_{s s} \\
\sigma_{s}=-f_{y k} & \text { for } \varepsilon \leq-\mathcal{E}_{s s} \\
\varepsilon_{s s}=\frac{f_{y k}}{E_{s}} &
\end{array}
$$

where $E_{s}$ - modulus of elasticity of profile or reinforcing steels. The above given formulae also apply to profile steel by replacing $f_{y k}$ with $f_{H y k}$.

The resistance of the composite cross-section is reached when either ultimate compressive strain in concrete $\varepsilon_{c u l}$ or ultimate tensile strain in steel $\varepsilon_{s u}$, or ultimate tensile strain in steel profile $\varepsilon_{H s u}$ is reached anywhere in that section. The equilibrium equation of the bending moments about the horizontal axis of the $\mathrm{RC}$ core rectangle takes the following form:

$$
\begin{gathered}
\sigma_{H f} F_{H f} 0.5\left(t+t_{f}\right)+\int_{x_{0}}^{t} \sigma_{H s}\left(x^{\prime}-0.5 t\right) d F_{H s}+ \\
\int_{0}^{x} \sigma_{c}\left(0.5 t-x^{\prime}\right) d A_{c}+\sigma_{s 1} F_{a 1}\left(0.5 t-t_{1}\right)+\sigma_{s 2} F_{a 2}\left(0.5 t-t_{2}\right)-M=0
\end{gathered}
$$

where: $t$ - height, $b$ - width of the RC rectangular core, respectively, $F_{a 1}, F_{a 2}$ - areas of reinforcing steels in compression and in tension, respectively, $t_{1}, t_{2}$ - coordinates describing the locations of compressive and tensile rebars, respectively, $\sigma_{s 1}, \sigma_{s 2}-$ stresses in steels in compression and in tension, respectively, $F_{H f}, t_{f}$ - area and thickness of the lower flange, $F_{H s}, t_{s}$ - area and thickness of the web, $x_{0}$ - coordinate of the upper edge of web, $\sigma_{H f}-$ stress referring to the middle thickness of the lower flange, $\sigma_{H s}$ - stress function referring to the web, $x$ - coordinate describing the location of neutral axis, $x^{\prime}$ - vertical coordinate of any point of the section, $0 \leq x, x^{\prime} \leq t$. Coordinates $x, x^{\prime}$ are measured from the upper edge of the section.

The assumption that plane sections remain plane is described as

$$
\varepsilon=\left(1-\frac{\xi^{\prime}}{\xi}\right) \varepsilon^{\prime}
$$

where: $\xi^{\prime}=x^{\prime} / t, \xi=x / t$ - dimensionless coordinate describing the location of neutral axis, $\mathcal{E}^{\prime}$ - maximum compressive strain in concrete.

The normalized ultimate bending moment $m_{H R m}$ determining the resistance of the BH beam is derived in terms of strains by integrating the equilibrium equation of the bending moments 
(6) about the horizontal axis of the RC core rectangle, taking into account the physical and geometrical relationships (1) - (5), (7):

$$
\begin{array}{cc}
m_{H R m}=0.5\left(1+\xi_{f}\right) \rho_{f} f_{H y k} / f_{c m}\left[\delta_{k 2}+\delta_{k 2+1}(1-1 / \xi) \varepsilon^{\prime} / \varepsilon_{s s}\right]+\rho_{s} f_{H y k} / f_{c m}[-0.5(1- \\
\left.\left.\xi_{0}\right)+\quad\left(1-\xi_{0}^{2}\right)(0.5 / \xi+1)-1 /(3 \xi)\left(1-\xi_{0}^{3}\right)\right]+m_{R m}
\end{array}
$$

where: $m_{H R m}=M_{H R m} /\left(b t^{2} f_{c m}\right), M_{H R m}$ - the ultimate bending moment, $\xi_{0}=x_{0} / t, \xi_{f}=t_{f} / t, \quad \rho_{f}$ $=F_{H f} / b t, \rho_{s}=F_{H s} / b t, \varepsilon_{s s}=f_{H y k} / E_{s}, \delta_{i}=\left((-1)^{\mathrm{i}}+1\right)$. The term $m_{R m}$ refers to the rectangular RC core and was derived from the work [10]:

$$
\begin{gathered}
m_{R m}=(1 /(k-2))\left\{\begin{array}{l}
0.5\left(W_{1}+(1 /(k-2))\right) \xi+0.5\left[-W_{1}+0.5 k_{2}-((1 /(k-2))] \xi^{2}+\right. \\
-(1 / 3) k_{2} \xi^{3}-\left(W_{2} /\left((k-2) W_{3}\right)\right)\left[0.5 \ln W+\xi-\left(W / W_{3}\right) \ln W\right]
\end{array}\right\} \\
+\mu_{1} \frac{f_{y k}}{f_{c m}}\left(0.5-\xi_{1}\right)\left\{-\delta_{k 1}+\delta_{k 1+1} \frac{\varepsilon^{\prime}}{\varepsilon_{s s}}\left(1-\frac{\xi_{1}}{\xi}\right)\right\}+\mu_{2} \frac{f_{y k}}{f_{c m}}\left(0.5-\xi_{2}\right)\left\{\delta_{k 2}+\delta_{k 2+1} \frac{\varepsilon^{\prime}}{\varepsilon_{s s}}\left(1-\frac{1-\xi_{2}}{\xi}\right)\right\} \\
m_{R m}=\frac{M_{R m}}{b t^{2} f_{c m}} \\
\xi=\frac{\left(1-\xi_{1}\right) \varepsilon_{c u 1}}{-\varepsilon_{s u}+\varepsilon_{c u 1}}, \quad \mathcal{E}^{\prime}=\varepsilon_{c u 1},-\left(\frac{1}{\xi}-1\right) \mathcal{E}^{\prime}=\varepsilon_{s u}
\end{gathered}
$$

where: $k_{2}=\varepsilon^{\prime} /\left(\varepsilon_{c l} \xi\right), W_{l}=k-k_{2} \xi, W_{2}=k(k-2)+1, W_{3}=(k-2) k_{2}, W=1+(k-2) k_{2} \xi$; $=0,5\left((-1)^{k}+1\right) ; \mu_{1}, \mu_{2}-$ reinforcement ratios of steels in compression and in tension, respectively, $\xi_{1}=t_{1} / t, \xi_{2}=t_{2} / t$.

The formulae (8) - (11) describe the resistance $m_{H R m}$ of the considered steel and concrete composite cross-section subjected to bending.

\section{Experimental study}

In order to verify the obtained analytical solution, the bending tests were carried out in the Building Research Institute on separate BH 27-350 and BH 20-300 beams. For the RC rectangular core, the reinforcing steel with yield stress $f_{y k}=500 \mathrm{MPa}$ was used, while for the profile steel with yield stress $f_{H y k}=460 \mathrm{MPa}$. The BH beams were loaded up to failure. The setup of the tests is presented in Fig. 3. The scope of the tests covered the determination of the failure loads and the corresponding strains. In each load step, the strains in concrete $\varepsilon_{c}$, reinforcing steel $\mathcal{E}_{s I}$ in compression and profile steel $\varepsilon_{H f}$ were measured using strain gauges located in the middle section of the $\mathrm{BH}$ beam (Fig. 4). The strains in reinforcing steel in tension $\mathcal{E}_{s 2}$ were determined by taking into account the assumption that plane sections remain plane.
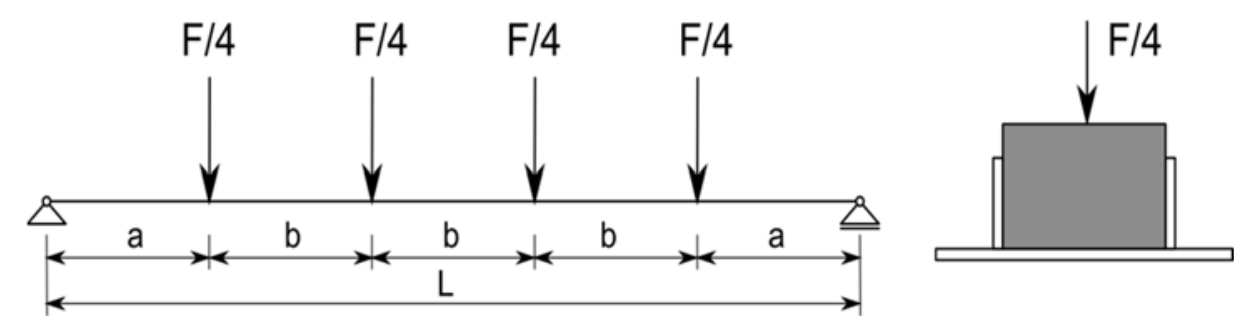

Fig. 3. Setup of the tests. 

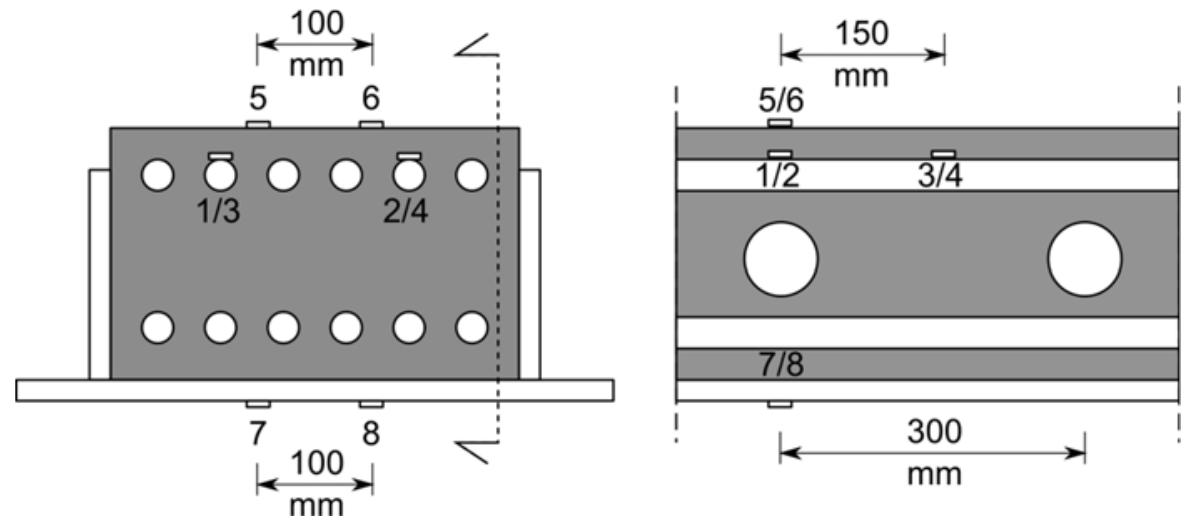

Fig. 4. Strain gauge arrangement.

\subsection{Beam BH 27-350}

Beam BH 27-350 was manufactured from concrete with the mean compressive strength $f_{c m}=58 \mathrm{MPa}$ (concrete grade $\mathrm{C} 50 / 60 ; E_{c m}=37 \mathrm{GPa}$ ), which was approved by standard testing. This beam had the following geometric characteristics:

$$
\begin{aligned}
& t=0.27 \mathrm{~m} ; b=0.35 \mathrm{~m} ; a=1.54, b=1.6 \mathrm{~m}, L=7.88 \mathrm{~m} ; \\
& t_{1}=25+8+12.5=45.5 \mathrm{~mm} ; \xi_{1}=t_{1} / t=0.17 ; \\
& t_{2}=40+8+12.5=60.5 \mathrm{~mm} ; \xi_{2}=t_{2} / t=0.22 ; \\
& \mu_{1}=\mu_{2}=29.45 /(27 \cdot 35)=0.0312 \cong 3 \% ; \\
& t_{f}=12 \mathrm{~mm} ; \xi_{f}=t_{f} / t=0.06 ; t_{s}=6 \mathrm{~mm} ; \\
& x_{0}=132.5 \mathrm{~mm} ; \xi_{0}=x_{0} / t=0.491 ; \\
& \rho_{f}=F_{H f} / b t=(60.2 \cdot 1.2) /(27 \cdot 35)=7.6 \% ; \\
& \rho_{s}=F_{H s} / b t=(2 \cdot 13.25 \cdot 0.6) /(27 \cdot 35)=1.7 \% ;
\end{aligned}
$$

Table 1. Bending test results of the BH 27-350 beam.

\begin{tabular}{|c|c|c|c|c|}
\hline Concrete & $\begin{array}{c}\text { Compressive } \\
\text { reinforcing steel }\end{array}$ & $\begin{array}{c}\text { Tensile } \\
\text { reinforcing steel }\end{array}$ & Profile steel & $\begin{array}{c}\text { Failure bending } \\
\text { moment }\end{array}$ \\
\hline$\varepsilon_{c}[\%$ o $]$ & $\mathcal{\varepsilon}_{s 1}[\% o]$ & $\varepsilon_{s 2}[\%$ o $]$ & $\mathcal{E}_{\boldsymbol{H} f}[\%$ o] & $\boldsymbol{M}_{\boldsymbol{u}}[\mathrm{kNm}]$ \\
\hline-3.5 & -2.6 & 0.63 & 2.03 & 635 \\
\hline
\end{tabular}

The failure mechanism of the BH 27-350 beam occurred in the form of crushing of the concrete (Fig. 5). In Table 1, the mean measured values of strains and bending moment at failure are collected. The compressive strain in concrete reached the ultimate value $\varepsilon_{c}$ $=\varepsilon_{c u l}=-3.5 \%$ which is combined with $\left|\varepsilon_{s l}\right|=|-2.6 \% o|>\varepsilon_{s \mathrm{~s}}=2.5 \%$. This in turn means that plastic strains in the rebars in compression may have occurred. Based on the derived formulae (8) - (11) the value $M_{H R m}=634.7 \mathrm{kNm}$ was calculated which is close to the failure bending moment $M_{u}=635 \mathrm{kNm}$. This shows very good convergence between the analytical solution $M_{H R m}$ and the test result in ultimate bending moment $M_{u}$ (relative difference $0.05 \%$ ). 


\subsection{Beam BH 20-300}

On the basis of the standard testing performed by the manufacturer, the mean compressive strength of the beam's concrete was determined as $f_{c m}=53 \mathrm{MPa}$ (concrete grade C45/55; $\left.E_{c m}=36 \mathrm{GPa}\right)$. The $\mathrm{BH} 20-300$ beam was characterized by:

$t=0,2 \mathrm{~m} ; b=0.3 \mathrm{~m} ; a=1.14, b=1.2 \mathrm{~m}, L=5.88 \mathrm{~m}$;

$t_{1}=25+8+10=43 \mathrm{~mm} ; \xi_{1}=t_{1} / t=0.215$

$t_{2}=40+8+10=58 \mathrm{~mm} ; \xi_{2}=t_{2} / t=0.29 ;$

$\mu_{1}=\mu_{2}=18.84 /(20 \cdot 30)=0.0314 \cong 3 \%$;

$t_{f}=12 \mathrm{~mm} ; \xi_{f}=t_{f} / t=0,06 ; t_{s}=8 \mathrm{~mm}$

$x_{0}=95 \mathrm{~mm} ; \xi_{0}=x_{0} / t=0.475$;

$\rho_{f}=F_{H f} / b t=(55.8 \cdot 1.2) /(20 \cdot 30)=11.2 \%$;

$\rho_{s}=F_{H s} / b t=(2 \cdot 9.5 \cdot 0.8) /(20 \cdot 30)=2.5 \%$;

Table 2. Bending test results of the BH 20-300 beam.

\begin{tabular}{|c|c|c|c|c|}
\hline Concrete & $\begin{array}{c}\text { Compressive } \\
\text { reinforcing steel }\end{array}$ & $\begin{array}{c}\text { Tensile } \\
\text { reinforcing steel }\end{array}$ & Profile steel & $\begin{array}{c}\text { Failure bending } \\
\text { moment }\end{array}$ \\
\hline$\varepsilon_{c}[\% o]$ & $\mathcal{E}_{s 1}[\% o]$ & $\boldsymbol{\varepsilon}_{s 2}[\% o]$ & $\boldsymbol{\varepsilon}_{\boldsymbol{H} f}[\% o]$ & $\boldsymbol{M}_{\boldsymbol{u}}[\mathrm{kNm}]$ \\
\hline-3.5 & -2.3 & 0.46 & 2.42 & 374 \\
\hline
\end{tabular}

The BH 20-300 beam underwent the same form of failure, i.e. crushing of the concrete (Fig. 5). The mean measured values of strains and bending moment at failure are given in Table 2. The compressive strain in concrete reached the ultimate value $\varepsilon_{c}=\varepsilon_{c u l}=-3.5 \%$. It is worth noting that plastic strains in the lower flange may have occurred as $\varepsilon_{H f}=2.42 \%$ o $>\varepsilon_{\mathrm{ss}}=$ 2.3\%o. According to the derived formulae (8) - (11) the value $M_{H R m}=366.4 \mathrm{kNm}$ was calculated which is close to the failure bending moment $M_{u}=374 \mathrm{kNm}$. This confirms good convergence between the analytical solution and the test results in ultimate bending moment as well (relative difference: $2 \%$ ).

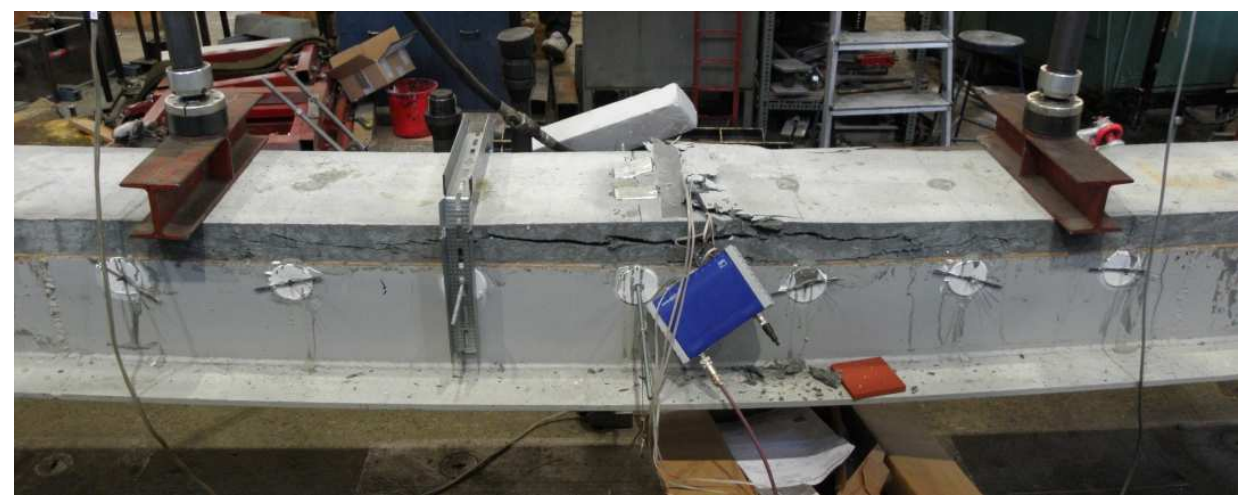

Fig. 5. The characteristic failure mode of the BH 27-350 beam.

\section{Summary and conclusions}

The analytical solution was developed for the resistance of composite steel and concrete beams subjected to bending, based on the nonlinear stress-strain relationship for concrete. The solution closely reflects the actual behavior of concrete in compression. This solution 
shows good convergence with the test results in ultimate bending moment. Such a formulation enables the analysis of the behavior of the cross-section of composite steel and concrete beams in the post-critical phase, and in this respect, it can be regarded as a valuable solution in the theory of composite structures. Thus, it can be very useful as far as the prediction and verification of test results are concerned.

\section{References}

1. J. Derysz, P.M. Lewiński, P.P. Więch, Proc. Eng. 193 (2017).

2. P.M. Lewiński, J. Derysz, S. Dudziak, P. Więch, Proc. of the fib Symposium (2019).

3. Y. Liu, A. Alkhatib, Canadian J. of Civ. Engng, 40, 9 (2013).

4. U. Kuhlmann, K. Kürschner, Composite Construction in Steel and Concrete V, ASCE, 534-543 (2006).

5. U. Kuhlmann, U. Breuninger, Composite Construction in Steel and Concrete IV, ASCE, 438-449 (2002).

6. Stahlbaukalender (Ernst \& Sohn, Wiley Brand, Berlin, 2018).

7. EN 1993-1-1: 2005 Eurocode 3: Design of steel structures - Part 1-1 General rules and rules for buildings.

8. EN 1994-1-1: 2004 Eurocode 4: Design of composite steel and concrete structures Part 1-1 General rules and rules for buildings.

9. EN 1992-1-1: 2010 Eurocode 2: Design of concrete structures - Part 1-1 General rules and rules for buildings.

10. M. Lechman, Transport. Res. Proc.14 (2016). 